\title{
The efficiency of STAT's order throughout alert technology for the nurse's mobile station in Taiwan: A trajectory study
}

\author{
Bi-Lian Chen*1,2 \\ ${ }^{1}$ Institution of Nursing, National Yang-Ming University, Taiwan, Province of China \\ ${ }^{2}$ Department of Nursing, Taichung Veterans General Hospital, Taichung City, Taiwan, Province of China
}

\author{
Received: October 23, 2017 \\ Accepted: March 20, 2018 \\ Online Published: March 25, 2018 \\ DOI: $10.5430 /$ jnep.v8n8p47 \\ URL: https://doi.org/10.5430/jnep.v8n8p47
}

\begin{abstract}
Nursing information system combined with computerized physician order entry is a new technology on patient medication safety. With the help of clinical decision support and the alert reminder of the mobile station, the medication administration will be more precise. The purpose of this study was to predict the change of time on Stat Order before and after the implementation of the decision alert system. Design: Throughout a longitudinal study and a nested design-level 1 was the frequency of time on Stat Order (including the baseline, one up to six times); level 2 was the subject (nurses). Settings: The subjects were divided into two groups: before (paper group) and after (computer group with flash of alert to remind nurses) implementation. The data of nursing information system was used to collect the administration medication of time on Stat Order. Participants: There were 198 nurses enrolled and 2,376 time on Stat Order in this study. The study was carried out between July to October 2008. STATA 12.0 was adopted for descriptive statistics and multilevel regression analysis. The result showed that the mixed regression model of time on Stat Order on computer group was significantly reduced than on paper group (95\% CI: $-99.05 \sim-61.65, p<.001)$. Furthermore, it also showed a significantly reduced time on each visit (95\% CI: $-13.63 \sim-9.89, p<.00)$. The inter-correlation value was $.66 \sim .67$. We recommended integrating this new alert technology, a high quality and timely method, with nurse's routine work to improve medication administration on health care service.
\end{abstract}

Key Words: Medication administration systems, Computerized physician order entry system, Decision marking, Alert's technology

\section{INTRODUCTION}

Patients' safety should be the priority in any advanced hospitals. A leading nursing information system could bring a win-win situation for both the patients and the health workers. ${ }^{[1,2]}$ Clinical Decision Support and Evidence Guideline has become the mainstream with the evolution of electronic medicine record. However, the study of the effectiveness of a long term tracking on nurses' performing STAT Orders, through the clinical decision support system of mobile station integrating the nursing information system with CPOE (computer physician order entry), is rarely found. Clinical Decision Support and Evidence Guideline provide clinicians or nurse practitioners a computerized environment in writing orders. ${ }^{[1]}$

\footnotetext{
*Correspondence: Bi-Lian Chen, PhD Candidate, Informatics Nursing Specialist; Email: blchen25@ gmail.com; Address: Institution of Nursing, National Yang-Ming University, Taiwan, Province of China.
} 
The organization committee of hospital association suggested in 2010 that all hospitals and pharmacies should use electronic prescriptions to reduce prescribing errors inherent in paper-based systems. ${ }^{[3]}$ They eliminate fatal medical errors derived from legal and ethical issues due to poor handwriting. ${ }^{[2]}$ Human factor is one of the most important pushing hands in promoting decision-making support system. The system was designed to be a user-friendly communication tool on patient's health care. ${ }^{[2]}$ Decision support systems may be influenced by the hardware, technical support, data quality, workflow integration and timeliness of care. ${ }^{[4]}$ Available hardware, technical support and training, workflow integration and proper, timely and time-saving clinical message were the factors that affect the system. ${ }^{[5-7]}$ Alerts and reminders are the two functions of the decision-making support system. Colors and graphics are used to distinguish the levels of severity and, as well as a way to note physicians. ${ }^{[2,8]} \mathrm{An}$ alert has to be classified by severity. Clinical alerts could be the tool to change medical staff's behaviors and enhance the quality of health care. ${ }^{[2]}$

Traditional paper based orders often caused confusion due to less cleared writing. It took time for nurses processing the orders. Computer-based orders, on the contrary, eliminated the problem, and can be checked on line promptly. Our hospital has adopted information technology in clinical orders for more than twenty years, but it lacked the dynamic and timely reminders in nursing information system. Therefore, this study was focused on the effectiveness of nurses' using reminders of the decision-making support system on mobile station to save time on Stat orders.

\subsection{Literature review}

\subsubsection{Decision support systems, clinical (CDSS)}

CDSS was defined as a computerized information system. The original data from electronic medical records that integrated the information of patients and clinical are converted to useful information to help nurses to give appropriate medication recommendations and clinical judgment for Information Technology CDSS. ${ }^{[2]}$ It is extremely helpful for clinical nurses to take time to figure orders out and to take medicine. The reductions in transcription to promote high performance of electronic nursing records that change paper-based documentation systems.

\subsubsection{Computerized physician order entry (CPOE)}

An estimated 522,000 serious medication errors are occurred each year in the United States. The use of computerized physician order system can eliminate medication errors. ${ }^{[3,9]}$ CPOE is automating the ordering process to make sure it is standardized, legible, and complete. CPOE systems have helped health-worker to increase patients' safety and to re- duce medication errors. It improves nursing work-flow efficiency and the clarity of the prescriptions. It is easier to manage than paper records. It is cost saving and it will continue to move toward the goal of near miss. ${ }^{[10,11]}$

\subsubsection{CPOE and CDSS}

The reduced medication error rates were $13 \%$ to $86 \%$ when combined computerized physician order entry with clinical decision support systems. ${ }^{[3]}$ The nurses, in handling routine doctor's order per patient, decreased 0.8 minutes per hour when combined computerized physician order system (CPOE) with electronic medical record (EMR). The routine time for the nurse in handling orders reduced by $25 \%$. Another study showed CPOE for them saved $2 \%$ extra time. ${ }^{[5,7]}$ Clinical judgment and decision support system allows nurses to feel trustworthy so as to provide effective care to the patients. $^{[12]}$

In conclusion, CPOE AND CDSS provide health workers a timely and complete assist in taking care of patients. It is superior to traditional paper based working system. That is why a new computer based working system must be done on nurse's medication administration. The purpose of this study is to predict the change of time on Stat Order (TOSO) by decision technology before and after the alert implementation. Research Hypothesis that it can shorten the time of clinical physician orders entry (CPOE) effectively with the new flashes to remind nurse's administration than that of paper based system.

\section{Methods}

Through longitudinal study, and nested (cluster) design, level 1 was visit times of TOSO (including baseline and 1 to 6 times). Level 2 was subject of nurse. Subjects are divided into two groups: before (called paper group) and after (computer group with flash alert to remind nurse).

This study was approved by the IRB TCVGH No: CE12226 for Ethics approval.

Theoretical was based on Longitudinal, panel, nested and growth-curve models. ${ }^{[13]}$

Equation was Longitudinal Data:

$\mathrm{y}_{i j}=$ value of ith observation (time) on the jth subject, measures at time $\mathbf{t}_{i j}$. (Equation: $\mathrm{Y}_{i j}(\mathrm{TOSO})=\beta_{0}+\beta_{1} \mathrm{X}_{1 i j}$ (Pre) $+\beta_{2} \mathrm{X}_{2 i j}$ (Group) $+\beta_{3} \mathrm{X}_{3 j}$ (Visit) $\left.+\in \mathrm{ij}\right)$.

Independent variable was subject (j): 198 nurses (nurse identifier: j);

Group: group 0 was indicated (paper-based system [no flash alert]); group 1 was showed (computer-based system [with flash alert]); 
Visit (i) Pre: It meant baseline, also called code of Times 0; Times 1 to 6: that meant post-intervention from week 1 to 6(i);

Outcome measure was response variable TOSO: Time of administration (Time of Stat Order, TOSO) (Yij) (time of sign on order by nurse minus physician order's time, units in minute).

Sampling was participants and interventions: 198 nurses received alert of flash on CDSS which reminded them to process medication of stat orders.

We applied the drugs database from hospital information system. Paper-based data were collected from July 1 to August 31, 2008; while computer based data was collected from September 2 to October 31, 2008. There were 2,440 pre-intervention of Evac enema orders were collected while 2,520 post-intervention of Evac enema orders were collected.

After cross compared the before and after data with the same nurse giving the same medication, only 198 nurses (j) were matched the pairing. A total of 2,376 numbers of observations (i) for long-term, multi-level linear data were analyzed. Data analysis was performed with STATA 12.0 for descriptive statistics and multilevel regression.

Adjusted mixed-effects logistic regression models including an interaction term of groups and times of visit were adopted. Across six-time visits of linear trend test and transpose of square root of visit $\left(\right.$ visit $\left.^{2}\right)$ for non-linear trend were tested. The residual intra-class correlation coefficient (I.C.C.) was calculated.

\section{Results}

The results of mixed regression model showed the time of stat order (TOSO) on Computer group was significantly reduced than that on paper group (95\% CI: -99.05 -61.65, $p<$ $.001)$.

Demographics data as showed on Table 1, it took longer time for 1 to 3 visits than 4 to 6 visits; and the diversity of the first three visits were larger than the last three visits. According to the graph, the pretest and posttest between groups was nonlinear. Pretest and posttest on stat showed 95\% confidence interval (see Figure 1).

Transposed diagram (visit ${ }^{2}$ : square root of time), the original curve approach has a straight line (see Figure 2).

Besides, we found a significantly reduced time on each visit (95\% CI: -13.63 -9.89, $p<.00$ ). Intraclass correlation were $.66 \sim .67$. We analyzed mixed effect as below about time estimate in the two groups with $95 \%$ confidence intervals (see Table 2).

Table 1. Time difference of before and after times among paper and computer group

\begin{tabular}{|c|c|c|c|c|c|}
\hline & Nurses & Minimum & Maximum & Mean & SD \\
\hline \multicolumn{6}{|c|}{ Paper-Based group } \\
\hline Pre & 198 & 5 & 861 & 323.44 & 198.28 \\
\hline Time 1 & 198 & 1 & 679 & 191.93 & 150.57 \\
\hline Time 2 & 198 & 1 & 595 & 151.30 & 119.64 \\
\hline Time 3 & 198 & 1 & 484 & 130.68 & 108.72 \\
\hline Time 4 & 198 & 1 & 439 & 127.64 & 97.66 \\
\hline Time 5 & 198 & 1 & 439 & 128.45 & 95.34 \\
\hline Time 6 & 198 & 1 & 439 & 123.90 & 95.23 \\
\hline \multicolumn{6}{|c|}{ Computer-Based group } \\
\hline Pre & 198 & 1 & 708 & 183.70 & 157.18 \\
\hline Time 1 & 198 & 1 & 495 & 111.72 & 113.83 \\
\hline Time 2 & 198 & 1 & 435 & 75.70 & 83.06 \\
\hline Time 3 & 198 & 1 & 351 & 64.17 & 70.95 \\
\hline Time 4 & 198 & 1 & 353 & 58.30 & 60.87 \\
\hline Time 5 & 198 & 1 & 297 & 57.61 & 58.22 \\
\hline Time 6 & 198 & 1 & 297 & 59.95 & 59.31 \\
\hline \multicolumn{6}{|c|}{ Total amount of nurses $396(j)$} \\
\hline Total am & servatic & & & & \\
\hline
\end{tabular}




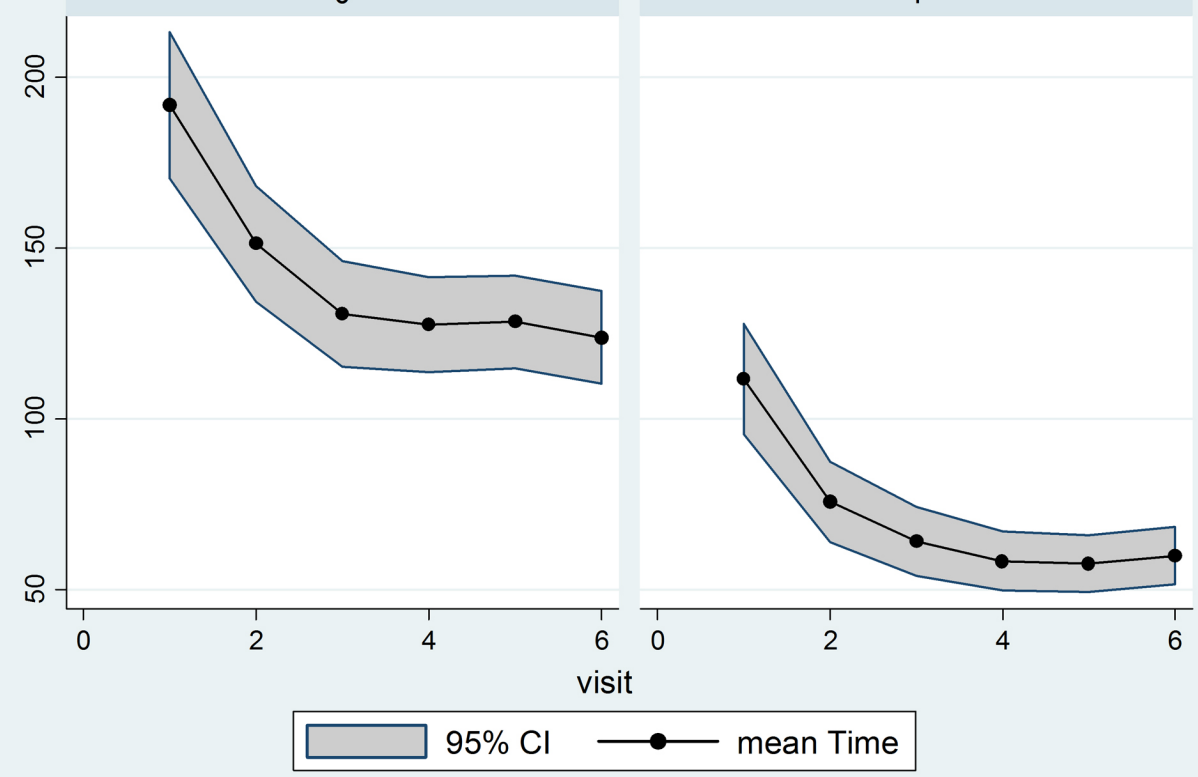

Graphs by group

Figure 1. 95\% CI of pretest and post 1-6 times between group

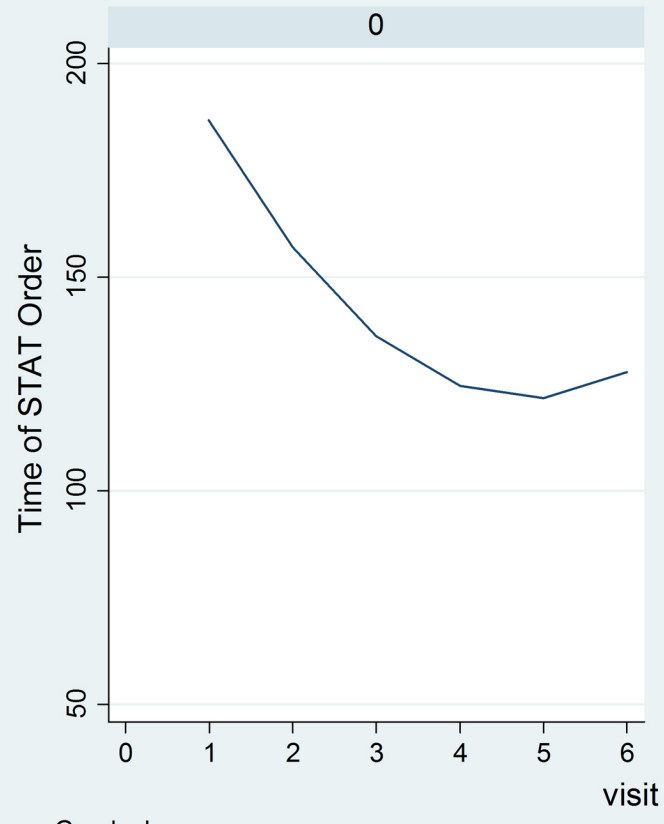

1

Graphs by group

Figure 2. Transposed graph in two groups

\section{Discussion}

As O'Meara ${ }^{[2]}$ pointed out that the decision support methods are warning (Alerts) and tips (reminders) which were used in decision support of advanced technologies. Clinical warning system (clinical alerts) can be used as a tool to change medical staff' behavior and improve the quality of health care. Keohane et al. and Moxey et al. ${ }^{[3,4]}$ pointed out that the key to success is the timeliness of decision support systems 
(timeliness). We believe that the benefits of intervention as a "real-time". This is a new innovation to integrate alert on medication administration with information technology in our nursing information system. We have proved this based on our nurses daily practice on medication administration. However, there are still some rooms for improvement. One is always check CPOE from computer system instead of paper based orders; the other is verify the priority of orders. For example, stat order is always the first to take. We hope nurses can react as soon as they see the signal that reminds them the urgency condition upon medication administration.

Table 2. Time estimate in the two groups with $95 \%$ confidence intervals

\begin{tabular}{|c|c|c|c|c|}
\hline & \multirow{2}{*}{ Correlation coefficient (Coef.) } & \multicolumn{2}{|l|}{$95 \% \mathrm{CI}$} & \multirow{2}{*}{$p$} \\
\hline & & Upper & Lower & \\
\hline \multicolumn{5}{|l|}{ Xtreg } \\
\hline Constant & 183.5003 & 196.724 & 170.276 & .000 \\
\hline Group & -80.35421 & -61.653 & -99.055 & .000 \\
\hline Visit & -11.76465 & -9.898 & -13.631 & .000 \\
\hline Gr_vis & 2.650505 & 5.2902 & 0.01077 & .049 \\
\hline Sigma_u & 79.30 & & & \\
\hline Sigma_e & 56.06 & & & \\
\hline$\rho$ & 0.6668005 & 0.7026 & 0.6293 & \\
\hline Log like lihood & $-13,446.173$ & & & \\
\hline \multicolumn{5}{|l|}{ Xtreg } \\
\hline Constant & 225.2705 & 240.781 & 209.759 & .000 \\
\hline Group & -80.35421 & -61.762 & -98.946 & .000 \\
\hline Visit & -43.0923 & -36.656 & -49.528 & .000 \\
\hline Gr_vis & 2.650505 & 5.2226 & 0.0743 & .044 \\
\hline Visit $^{2}$ & 4.475379 & 5.357 & 3.593 & .000 \\
\hline Sigma_u & 79.46 & & & \\
\hline Sigma_e & 54.71 & & & \\
\hline$\rho$ & 0.6784067 & 0.7134 & 0.6417 & \\
\hline Log like lihood & $-13,397.906$ & & & \\
\hline \multicolumn{5}{|c|}{ Xtmixed (by group) } \\
\hline Constant & 225.2705 & 244.432 & 206.108 & .000 \\
\hline Group & -80.35421 & -62.662 & -98.046 & .000 \\
\hline Visit & -43.0923 & -31.742 & -54.442 & .000 \\
\hline Gr_vis & 2.650505 & 7.1933 & -1.8923 & .253 \\
\hline Visit $^{2}$ & 4.475379 & 6.030 & 2.920 & .000 \\
\hline \multicolumn{5}{|c|}{ Random-effects parameters } \\
\hline Sd (Residual) & 96.475 & 99.257 & 93.771 & \\
\hline
\end{tabular}

\section{Conclusions}

The computer group reduced about 126 minutes on each stat order (95\% CI: .010 5.29, $p<.049$ ). The result showed there was an interaction between groups and visits. We recommended to integrate this new technology of alert with nurse's medication administration to improve patients' safety. Actually the health care decision-making is timely with high quality. Implications of the study was Remind system did help nurses to reduce prescription time. Patients can receive medical care earlier and get healed; it can reduce medical costs and increase bed turnover rate, too. It is highly recommended to promote this reminder to other hospitals to support the management in decision making in medical, nursing and pharmacy. Limitations of the Study was for the longitudinal study, how to manage the missing data is a big issue. Due to the cost and time limited, we did follow fourteen weeks after intervention. Do a follow-up study for over six years, and find the trend of changing over time, identify each drug's 
effect, and learn cross-hospital's experiences were recommendations. The other limitation is the nurse co-sign the order delayed, that will be prolong the time.

\section{ACKNOWLEDGements}

Thanks for foundering by TCVGH-1017408B. We would like to thank professor Chi Chiao, Shiao-Chi Wu and all physicians and nurses who cooperated in this study.

\section{Conflicts of InTERest Disclosure}

The author declares that there is no conflict of interest statement.

\section{REFERENCES}

[1] Davis M. The Seven Stages of EMR Adoption: Majority of Hospitals Are in Stage 3 and Rising. Healthcare Executive. 2010; 25(3): 18.

[2] O'Meara E. The Effects of Electronic Documentation in the Ambulatory Surgery Setting AORN Journal. 2007; 86(6): 970-979. PMid:18068402

[3] Keohane CA, Bates DW. Medication Safety. Obstetrics and Gynecology Clinics. 2008; 35(1): 37-52. PMid:18319127 https: //doi.org/10.1016/j.ogc.2007.12.002

[4] Moxey A, Robertson J, Newby D, et al. computerized clinical decision support for prescribing: provision does not guarantee uptake. Journal of the American Medical Informatics Association. 2010 17(1): 25-33. PMid:20064798 https ://doi.org/10.1197/jami a. M3170

[5] Devine EB, Williams EC, Martin DP, et al. Prescriber and staff perceptions of an electronic prescribing system in primary care: a qualitative assessment. BMC Med Inform Decis Mak. 2010; 10: 72 PMid:21087524 https ://doi.org/10.1186/1472-6947-10-7 2

[6] Hakes B, Whittington J. Assessing the impact of an electronic medical record on nurse documentation time. Comput Inform Nurs. 2008; 26(4): 234-241. PMid:18600132 https ://doi.org/10.1097/01 NCN . $0000304801.00628 . a b$
[7] Shu K, Boyle D, Spurr C, et al. Comparison of time spent writing orders on paper with computerized physician order entry. Stud Health Technol Inform. 2001.

[8] Langemeijer MM, Peute LW, Jaspers MW. Impact of alert specifications on clinicians' adherence. Stud Health Technol Inform. 2011; 169: 930-934. PMid:21893882

[9] Jones S, Moss J. Computerized provider order entry: strategies for successful implementation. J Nurs Adm. 2006; 36(3): 136-139. https://doi.org/10.1097/00005110-200603000-00007

[10] Pirnejad H, Niazkhani Z, van der Sijs H, et al. Evaluation of the impact of a CPOE system on nurse-physician communication-a mixed method study. Methods Inf Med. 2009; 48(4): 350-360. PMid:19448880 https : //doi.org/10.3414/ME0572

[11] Teich JM, Petronzio AM, Gerner JR, et al. An information system to promote intravenousto-oral medication conversion. Proc AMIA Symp. 1999; 415-419.

[12] Campion Jr TR, Waitman LR, Lorenzi NM, et al. Barriers and facilitators to the use of computer based intensive insulin therapy. International Journal of Medical Informatics. 2011; 80(12): 863-871. PMid:22019280 https://doi.org/10.1016/j.ijmedinf . 201 1.10 .003

[13] Rabe-Hesketh S, Skrondal A. Multilevel and Longitudinal Modeling Using Stata, Second Edition: Stata Press; 2008 